\title{
A Novel Method to Investigate the Effect of Social Network "Hook" Images on Purchasing Prospects in E-Commerce
}

\author{
Mohamed R. Smaoui \\ School of Computer Science, McGill University, Montreal, QC, Canada \\ Correspondence should be addressed to Mohamed R. Smaoui; mohamed.smaoui@mail.mcgill.ca \\ Received 9 May 2017; Revised 15 August 2017; Accepted 25 September 2017; Published 30 October 2017 \\ Academic Editor: Roberto Natella \\ Copyright (c) 2017 Mohamed R. Smaoui. This is an open access article distributed under the Creative Commons Attribution License, \\ which permits unrestricted use, distribution, and reproduction in any medium, provided the original work is properly cited.

\begin{abstract}
Background. Social network visual shopping trends are growing e-commerce at unprecedented levels. Images are used as product marketing material; however, image posts are triggering very low consumer behavior and low sales conversion. Objective. To explore how online stores can increase the purchasing prospects of their products using images on social networks. Methods. We introduce a theoretical probabilistic model to estimate consumer behavioral intention and purchasing prospect on social networks, outline parameters that can be exploited to increase click-rate and conversion, and motivate a new strategy to market products online. The model explores increasing online stores' sales conversion by utilizing a product collection landing page that is marketed to consumers through a single "Hook" image. To implement the model, we developed a novel technological method that enabled online stores to post different "Hook" images on social networks and hyperlink them to the product collection landing pages they created. Results. Stores and marketers developed four types of "Hook" images: themed-collaged product images, single product images, lifestyle images, and model images. Themed-collaged product images accounted for $60 \%$ of consumer traffic from social network sites. Moreover, consumer purchasing click rate increased at least twofold (4.94\%) with the use of product collection landing pages.
\end{abstract}

\section{Introduction}

Online stores are an increasingly popular means for consumers to purchase products. Each year, the number of online stores continues to grow $[1,2]$. Marketers and businesses constantly bombard social network users with e-commerce product images that hyperlink to store pages. This segment of online consumers is believed to rely disproportionately on these images as a source of product information and a basis to engage in purchasing decisions $[3,4]$. In fact, users of platforms rich in visual content including Tumblr, Instagram, and Facebook have started to adopt the trend of visual shopping [5-7]. Needless to say, although social networks are primarily composed of images and hypermedia, engagement with images on social networks and their sales conversions are relatively low. Currently, only 1 to 2 percent of social network users engage in clicking on image posts [8]. Out of those who click, only 1 to 2 percent end up buying the actual e-commerce product from a store's website [9].

In the social network world, users accustomed to the culture of content consumption are influenced by their social circles and figures they consider influential. Concepts such as "attitudes" and "subjective norms" defined by the theory of reasoned action (TRA) [10] and the theory of planned behavior (TPB) [11] can be utilized to influence social network users' "behavioral intentions" to increase engagement with posts and purchasing prospects of products. To increase purchasing behavioral intention by influencing attitude, it is important to understand the ways that consumers behave, engage, and react to image posts on social networks in order to curate persuading images that engage users to potentially buy products [12, 13]. Perception of products is affected by consumer attention, interpretation, and stimulus [14-16]. Hence, the way we present these products online through images or videos can motivate, persuade, and stimulate the consumer to complete a sale transaction. Moreover, convenience, risk, and enjoyment have been found to be the three main perceptions affecting consumers' experience of online shopping and influencing their attitudes [17]. In this study, we will investigate the types of social network posts that lead to the highest consumer purchasing behavioral intentions and explore a strategy to optimize the marketing of those posts. 


\section{Background}

Several theories have aimed to explain the relationship between intentions and behaviors within human action. Among the well-known persuasion models of psychology, TRA predicts how individuals will behave based on preexisting behavioral intentions. The theory suggests that stronger intentions lead to increased effort to perform a behavior, increasing the likelihood that the behavior will be performed. Furthermore, the theory predicts that a person's intention to perform an action or behave in a certain way is influenced and motivated directly by their "attitude" towards the behavior and "subjective norms." While attitude towards a behavior can be defined as a person's positive or negative opinion regarding the behavior, subjective norms are one's perception of social pressure due to performing the behavior [18]. Subjective norms describe the pressure an individual feels to perform or not perform the behavior at hand.

The TPB further extends the TRA to include the notion of "perceived behavioral control" as a factor that influences behavioral intention. Perceived behavioral control initially originated from the self-efficacy theory (SET) [19] and can be defined as one's perceived ease or difficulty of performing a behavior. The TPB states that attitudes, subjective norms, and perceived behavioral control are all responsible for influencing behavior. The correlation between increased behavioral intention and behavior has been confirmed in many studies [20]. In the field of marketing, the TRA and TPB can be utilized to develop strategies to increase customer behavioral intention towards using or purchasing products and services. Changing a customer's attitude towards a product, service, or brand and focusing on ways to ameliorate subjective norms should lead to an increase in behavioral intention towards using a product or service.

Successful digital marketing strategies take into account the factors that influence a consumer's behavioral intention. Motivating consumers by understanding their needs and influencing their decision-making in e-commerce result in positive attitudes and subjective norms. As consumers have increasingly less time for physical shopping, convenience of online stores is an important decision-making factor in ecommerce [21-23]. The extended web assessment method (EWAM) [24] provides insights into the relevant criteria that influence customer behavior on e-commerce web sites. Some of the criteria include community engagement in electronic markets, complimentary products to maximize customer benefit, and state-of-the-art information technology features. In addition, user experience and design factors such as ease of use, interactivity, possibility of searching information, depth of information, and security all affect consumer behavioral intention and conversion potential [25-27]. The core of EWAM is built on the criteria of "perceived usefulness" of e-commerce applications, their "ease of use," and consumer "trust."

The EWAM has been built on concepts of the technology acceptance model (TAM) [28]. TAM is an information systems theory that explains how users come to accept and use a new technology. The model explains that the two factors that influence a user's decision to use a technology are "perceived usefulness" of the technology and its "perceived ease of use" [29]. Users' attitude towards a new technology is more favorable if they believe that the technology will benefit them or increase their performance. In addition, a user's attitude will be shaped by the degree to which they believe that using the technology would be free of effort. These theories have been the building blocks that shape and configure how online stores need to be designed to interact successfully with consumers online. Images and visual design of websites and social network posts contribute to the emotional appeal for consumers [30, 31] and impact trust [32].

The purpose of this paper is to explore how online stores can better utilize visual content on social networks to increase purchasing behavioral intentions of consumers. The work in this paper utilizes concepts of the EWAM, TRA, and TPB to develop a new marketing strategy for online stores to increase consumer engagement and e-commerce. In the next section, we motivate the proposed marketing strategy for visual content on social media and present a concrete implementation of the strategy online.

\section{Consumer Behavioral Intentions and Purchasing Prospect}

In this section, we walk the reader through the thought process that lead to the development of our proposed marketing strategy and the engineering of a tool to change how ecommerce images are posted on social media. We outline in this section a probabilistic representation to theoretically model consumer interaction with images and purchasing prospect on social networks. We present parameters that can be exploited to increase click-through rates and conversion. Moreover, we explore how one photo (posted on a social network) hyperlinked to a webpage containing a collection of multiple products (instead of a single product) can generate a higher behavioral intention and purchasing interest than marketing the entire collection of products separately (posted on a social network that each links to a separate sales page). The theoretical probabilistic models and assumptions are outlined in detail in this section, followed by a concrete implementation of the proposed marketing strategy in Methods.

3.1. Model 1: Modelling the Sale of a Product Online. To better understand how a large part of e-commerce is done through social media, we first outline the probability of an ecommerce post on a social network to generate some amount of Cash. We will equate Cash as a measure of the online store's TAM perceived usefulness of creating the post. Equation (1) uses concepts from the TPB to model the probability that a consumer on a social network platform will click on an ecommerce image and buy its product:

$$
P\left(\widetilde{P}_{\mathrm{SALE}}\right)=P\left(\widetilde{P}_{\mathrm{AB}}\right) * P\left(\widetilde{\mathrm{P}}_{\mathrm{SN}}\right) * P\left(\widetilde{P}_{\mathrm{PBC}}\right),
$$

where $\widetilde{P}_{\mathrm{AB}}$ is the attitude of the consumer towards the behavior of purchasing the product, $\widetilde{P}_{\mathrm{SN}}$ is the subjective norms associated with purchase of the product, $\widetilde{P}_{\mathrm{PBC}}$ is the perceived behavioral control of purchasing product $\widetilde{P}$, and $P\left(\widetilde{P}_{\mathrm{SALE}}\right)$ is the probability of a sale occurring. On a social network, 
a visually appealing image can promote a positive $\widetilde{P}_{\mathrm{AB}}$ for a consumer and increase the chances of a click. $\widetilde{P}_{\mathrm{SN}}$ can be influenced by family members, friends, or social influencer figures who might have shared or recommended the post. In addition, $\widetilde{P}_{\mathrm{SN}}$ can also be influenced by a combination of a post's likes, shares, tweets, pins, and comments.

Equation (1) suggests that the amount of money, Cash, an online store will make out of promoting a product to a consumer on a social network platform is the following:

$$
\begin{aligned}
\text { Cash }= & P\left(\widetilde{P}_{\mathrm{AB}}\right) * P\left(\widetilde{P}_{\mathrm{SN}}\right) * P\left(\widetilde{P}_{\mathrm{PBC}}\right) * \widetilde{P}_{\text {price }} \\
& -\left[C_{P}+C_{M}\right]
\end{aligned}
$$

where $\widetilde{P}_{\text {price }}$ is the price of the product displayed in the image post, $C_{P}$ is the production cost to create the product digital image, and $C_{M}$ is any cost attributed to marketing the product image to the single consumer on the social network platform.

On a population level of $n$ consumers who cumulatively viewed this post $n$ times, (2) extends to

$$
\begin{aligned}
\text { Cash }= & \sum_{i}^{n}\left[P_{i}\left(\widetilde{P}_{\mathrm{AB}}\right) * P_{i}\left(\widetilde{P}_{\mathrm{SN}}\right) * P_{i}\left(\widetilde{P}_{\mathrm{PBC}}\right) * \widetilde{P}_{\text {price }}\right] \\
& -\left[C_{P}+n * C_{M}\right] .
\end{aligned}
$$

On Facebook, we know that image page posts are clicked between $0.04 \%$ and $2 \%$ of the time on average [8]. This is referred to as an image's click-through rate (CTR). In fact, according to The Facebook Ads Benchmark Report images generally only have a $1.2 \%$ CTR. More precisely, CTR is an average of the total probability of images on Facebook to cause consumers to click on them, which in TPB constructs can be estimated as a function of the probability of an image to cause a positive attitude towards a consumer and the probability that the image has a positive subjective norm $\left(P\left(\widetilde{P}_{\mathrm{AB}}\right) * P\left(\widetilde{P}_{\mathrm{SN}}\right)\right)$. Equation (3) becomes

$$
\begin{aligned}
\text { Cash }= & \sum_{i}^{n}\left[\mathrm{CTR} * P_{i}\left(\widetilde{P}_{\mathrm{PBC}}\right) * \widetilde{P}_{\text {price }}\right] \\
& -\left[C_{P}+n * C_{M}\right] .
\end{aligned}
$$

Since CTR and $\widetilde{P}_{\text {price }}$ are constants, we can factor them out of the sum:

$$
\begin{aligned}
\text { Cash }= & \text { CTR } *\left[\sum_{i}^{n} P_{i}\left(\widetilde{P}_{\mathrm{PBC}}\right)\right] * \widetilde{P}_{\text {price }} \\
& -\left[C_{P}+n * C_{M}\right] .
\end{aligned}
$$

Some online stores experience a fixed purchasing percentage, $F$, for their online products of $2 \%$ [33]. Their studies show that, out of the entire traffic to a product's page, only $F$ consumers buy the product. This $F$ percentage value estimates product's "purchase rate" for all consumers. We will estimate $P_{i}\left(\widetilde{P}_{\mathrm{PBC}}\right)$ as this "purchase rate" and make (5) as follows:

$$
\text { Cash }=\mathrm{CTR} * n * F * \widetilde{P}_{\text {price }}-\left[C_{P}+n * C_{M}\right] .
$$

If consumers clicking the image have to visit an intermediate page before landing finally on the product page, the effect of the cash generated by the online store will be the following:

$$
\begin{aligned}
\text { Cash }= & \mathrm{CTR} * n * \mathrm{CTR}_{I} * F * \widetilde{P}_{\text {price }} \\
& -\left[C_{P}+n * C_{M}\right],
\end{aligned}
$$

where $\mathrm{CTR}_{I}$ is the click-through rate from the intermediate page to the product page. $\mathrm{CTR}_{I}$ can be influenced by many factors. If $\mathrm{CTR}_{I}$ is an automatic redirect, then it would have a value of 1 and not affect the value of Cash. However, if the consumer has to stop at the intermediate page and consume content or make other decisions, the value of $\mathrm{CTR}_{I}$ becomes a variable value between 0 and 1 . At its best, it conserves the amount of Cash an online store makes but has the potential to lower it. Hence, it does not make financial sense to have an intermediate page with 1 product. However, we would like to engage the reader and show in the next section that this is not generally true if the intermediate page contains multiple products.

3.2. Model 2: The Use of a Hook Photo. For the purpose of our study, let us define e-commerce marketing images on social networks as "Hook" images that are hyperlinked to an e-commerce sales webpage. A "Hook" image can portray a product or any visual content that is intended to engage consumer action. A "Hook" image can promote a single product, a certain lifestyle, a theme, design, or idea. If this image directs traffic directly to an e-commerce page of 1 product, the Cash generated for that product is calculated as follows:

$$
\text { Cash }=(\mathrm{CTR}+\delta) * n * F * \widetilde{P}_{\text {price }}-\left[C_{P}+n * C_{M}\right] .
$$

$\delta$ is introduced into the equation by the "Hook" photo. Positive $\delta$ mean that the designed e-commerce "Hook" photo was able to attract more than the average click-through rate. Negative $\delta$ means that the image is not successfully "hooking" consumers' engagement. In TPB and EWAM terms, the $\delta$ value can be influenced by attitudes, subjective norms, and perception. We will investigate this relation at the end of this section.

If the online store chooses to post the same "Hook" photo twice, each time linking to a different product, the result of the cash it makes is the following:

$$
\begin{aligned}
\text { Cash }= & {\left[(\mathrm{CTR}+\delta) * n * F * \widetilde{P}_{\text {price }}^{1}-n * C_{M}\right] } \\
& +\left[(\mathrm{CTR}+\delta) * n * F * \widetilde{P}_{\text {price }}^{2}-n * C_{M}\right] \\
& -C_{P}
\end{aligned}
$$

which is equivalent to

$$
\begin{aligned}
\text { Cash }= & {[(\mathrm{CTR}+\delta) * n * F] *\left[\widetilde{P}_{\text {price }}^{1}+\widetilde{P}_{\text {price }}^{2}\right] } \\
& -\left[2 * n * C_{M}+C_{P}\right] .
\end{aligned}
$$

Equation (10) holds if the 2 "Hook" photo posts are viewed by a disjoint set of consumers; that is, $n$ consumers are not 
the same consumers viewing both posts. The same consumer viewing the post twice will not necessarily click on both posts. The probability of them clicking on both posts is about the same probability as clicking on 1 post (there is a high chance that they will only click on one of them, since they appear to be the same post). Hence, if an online store is advertising these posts to the same consumer base, the amount of Cash they make at the end of the day should approximately be

$$
\begin{aligned}
\text { Cash }= & {\left[\frac{(\mathrm{CTR}+\delta)}{2} * n * F\right] *\left[\widetilde{P}_{\text {price }}^{1}+\widetilde{P}_{\text {price }}^{2}\right] } \\
& -\left[2 * n * C_{M}+C_{P}\right] .
\end{aligned}
$$

Publishing the same "Hook" image twice for 2 different products is not beneficial. In fact, by the same reasoning above, it has the potential of cutting down the final Cash by half. Equation (11) can also be rewritten as

$$
\begin{aligned}
\text { Cash }= & {[(\mathrm{CTR}+\delta) * n * F] *\left[\frac{\widetilde{P}_{\text {price }}^{1}}{2}+\frac{\widetilde{P}_{\text {price }}^{2}}{2}\right] } \\
& -\left[2 * n * C_{M}+C_{P}\right]
\end{aligned}
$$

and the potential of this action is equivalent to selling each product at half price.

Equation (13) presents what Cash would be if an online store posts 2 normal product images, each leading to a separate product page:

$$
\begin{aligned}
\text { Cash }= & {\left[\text { CTR } * n * F * \widetilde{P}_{\text {price }}^{1}-\left[n * C_{M}^{1}+C_{P}^{1}\right]\right] } \\
& +\left[\text { CTR } * n * F * \widetilde{P}_{\text {price }}^{2}-\left[n * C_{M}^{2}+C_{P}^{2}\right]\right],
\end{aligned}
$$

which is equivalent to

$$
\begin{aligned}
\text { Cash }= & {[\text { CTR } * n * F] *\left[\widetilde{P}_{\text {price }}^{1}+\widetilde{P}_{\text {price }}^{2}\right] } \\
& -\left[n *\left(C_{M}^{1}+C_{M}^{2}\right)+C_{P}^{1}+C_{P}^{2}\right] .
\end{aligned}
$$

The interesting case arises when the "Hook" image directs to an "intermediate" page that presents the 2 product images. The product images can be clicked, redirecting a consumer to its e-commerce product page. It follows from (7) and (8) that Cash becomes

$$
\begin{aligned}
\text { Cash }= & {\left[(\mathrm{CTR}+\delta) * \mathrm{CTR}_{I}^{1} * n * F * \widetilde{P}_{\text {price }}^{1}-C_{P}^{1}\right] } \\
& +\left[(\mathrm{CTR}+\delta) * \mathrm{CTR}_{I}^{2} * n * F * \widetilde{P}_{\text {price }}^{2}-C_{P}^{2}\right] \\
& -\left[n * C_{M}^{H}+C_{P}^{H}+C_{I}\right]
\end{aligned}
$$

where $C_{H}^{P}$ is the production cost to create the "Hook" image, $C_{M}^{H}$ is the cost to market the image to a single consumer, and $C_{I}$ is the cost to create the intermediate page. Equation (15) also equals

$$
\begin{aligned}
\text { Cash }= & {[(\mathrm{CTR}+\delta) * n * F] } \\
& *\left[\mathrm{CTR}_{I}^{1} * \widetilde{P}_{\text {price }}^{1}+\mathrm{CTR}_{I}^{2} * \widetilde{P}_{\text {price }}^{2}\right] \\
& -\left[n * C_{M}^{H}+C_{P}^{1}+C_{P}^{2}+C_{P}^{H}+C_{I}\right],
\end{aligned}
$$

where $\mathrm{CTR}_{I}^{1}$ is the click-through rate of product 1 on the intermediate page and $\mathrm{CTR}_{I}^{2}$ is the click-through rate of product 2 on the intermediate page, where $\mathrm{CTR}_{I}^{1}+\mathrm{CTR}_{I}^{2} \leq 1$ (assuming that a consumer would not click on both links). Three immediate questions arise:

(1) Does posting the "Hook" image twice leading to 2 different product pages generate more Cash than posting 1 "Hook" image that leads to an intermediate page with 2 product images? (In other words, does (12) produce more Cash than (16)?)

(2) Does posting the "Hook" image twice leading to 2 different product pages generate more Cash than posting twice the 1 "Hook" image that leads to an intermediate page with 2 product images?

(3) Does a "Hook" image leading to an intermediate page with 2 product links produce more Cash than posting 2 single product images?

There are several answers to question (1). If we assume that consumers click on both products at the same rate and only click on 1 product, then $\mathrm{CTR}_{I}^{1} \approx 0.5$ and $\mathrm{CTR}_{I}^{2} \approx 0.5$ and both (12) and (16) generate approximately similar Cash, provided that the cost of marketing and image production are similar in both cases. However, if the 2 products on the intermediate page are simultaneously related to the "Hook" image, more realistically some consumers will want to click on both products to satisfy the interest generated from the "Hook" image. Equation (16) then really becomes

$$
\begin{aligned}
& \text { Cash }=[(\mathrm{CTR}+\delta) * n * F] *\left[\left(\mathrm{CTR}_{I}^{1}+\mathrm{CTR}_{R}^{1}\right)\right. \\
& \left.* \widetilde{P}_{\text {price }}^{1}+\left(\mathrm{CTR}_{I}^{2}+\mathrm{CTR}_{R}^{2}\right) * \widetilde{P}_{\text {price }}^{2}\right]-\left[n * C_{M}^{H}\right. \\
& \left.\quad+C_{P}^{1}+C_{P}^{2}+C_{P}^{H}+C_{I}\right]
\end{aligned}
$$

where $\mathrm{CTR}_{R}$ is the click-through rate of returning consumers interested to view the other product on the page. At this point, (17) surpasses (12) in Cash provided that the costs incurred are not substantially different. It follows that the answer to question (2) is that having 2 posts with the same "Hook" image that leads to an intermediate page with 2 products will generate more than twice Cash of two same "Hook" image posts that lead to 2 different product pages.

The more important question is number (3). We need to compare (17) with (14). The key observation is that if the intermediate page is optimized to lure consumers to click on both products; hence increasing the respective $\mathrm{CTR}_{R}$, (17) can become as follows:

$$
\begin{aligned}
\text { Cash }= & {[(\mathrm{CTR}+\delta) * n * F] *\left[\widetilde{P}_{\text {price }}^{1}+\widetilde{P}_{\text {price }}^{2}\right] } \\
& -\left[n * C_{M}^{H}+C_{P}^{1}+C_{P}^{2}+C_{P}^{H}+C_{I}\right]
\end{aligned}
$$

meaning that posting 1 "Hook" image linked to an intermediate page with 2 product links can make more Cash than posting the 2 individual product images on a social network page. In addition, the marketing cost is cut by half, yet we incur an additional production cost for the "Hook" image 
that needs to be taken into account and the cost to create the intermediate page. This can be explained by the intermediate page increasing consumer stimulus by offering some kind of convenience, entertainment, persuasion, or interactivity. From this offering, an online store using a "Hook" image linked to an intermediate page can make $\Delta X$ more Cash where $\Delta X$ is

$$
\begin{aligned}
\Delta X= & \delta * n * F *\left[\widetilde{P}_{\text {price }}^{1}+\widetilde{P}_{\text {price }}^{2}\right]+n \\
& *\left(C_{M}^{1}+C_{M}^{2}-C_{M}^{H}\right)-C_{P}^{H}-C_{I} \\
\approx & \delta * n * F *\left[\widetilde{P}_{\text {price }}^{1}+\widetilde{P}_{\text {price }}^{2}\right]+n * C_{M}-C_{P}^{H} \\
& -C_{I} .
\end{aligned}
$$

This result is very powerful. Not only does an online store benefit from positive values of $\delta$ but also saves on the marketing cost of multiple image posts to consumers online. The lower the costs of creating the "Hook" image and the intermediate page, the higher $\Delta X$. Generalizing (17) to a "Hook" image that leads to an intermediate page with $k$ products can produce the following Cash:

$$
\begin{aligned}
\text { Cash }= & (\mathrm{CTR}+\delta) * n * F \\
& *\left[\sum_{i}^{k}\left(\mathrm{CTR}_{I}^{i}+\mathrm{CTR}_{R}^{i}\right) * \widetilde{P}_{\text {price }}^{i}\right]-n * C_{M}^{H} \\
& -\sum_{i}^{k} C_{P}^{i}-C_{P}^{H}-C_{I} .
\end{aligned}
$$

Optimizing $C_{R}^{i}$ on the intermediate page gives the online store the potential of making $\Delta Y$ more Cash than posting the individual product images on social networks:

$$
\begin{aligned}
\Delta Y= & \delta * n * F *\left[\sum_{i}^{k} \widetilde{P}_{\text {price }}^{i}\right]+\sum_{i}^{\mathrm{k}} C_{M}-C_{M}^{H}-C_{P}^{H} \\
& -C_{I} .
\end{aligned}
$$

The online store saves on the cost to market all the product images on social platforms and incurs the cost to create a "Hook" image, the cost to market it, and the cost to assemble the products into an intermediate page. The consumer can reinvest any savings into additional marketing for the "Hook" image to reach a wider audience and build greater engagement.

3.3. Model Insights. The conclusion of our theoretical model suggests the use of intermediate product collection pages to influence consumer behavioral intention and sales conversion. Instead of marketing several product images on social networks, online stores should market one image that links to a page displaying the several products. The models suggest that this can potentially increase purchasing prospects of products given that the $\delta$ parameter in the model is positive.

The $\delta$ parameter captures the effect of a "Hook" image in inducing consumers to click through the marketing image and engage with product collection pages. For this "Hook" image marketing strategy to result in higher e-commerce, the concrete implementation of the strategy must attract a higher interest in consumer click-through on social networks. Users will want to find the products that they see in a "Hook" image. Repeatedly clicking on "Hook" images that take users to unrelated products or to a product collection page that is not as user friendly as social network pages can spoil users' experience. Negative experiences with "Hook" images and product collection pages can deter users from clicking and negatively affect $\delta$ variable in the model.

To work towards creating a positive experience for consumers and ensuring a positive $\delta$, constructs of the EWAM model can be used in a concrete application of the proposed marketing strategy. In essence, $\delta$ in the model capturing the clicking behavior of consumers can be modelled as a function of the perceived usefulness (PU), ease of use (EU), and trust $(T)$ constructs of the EWAM model:

$$
\delta=f(\mathrm{PU}+\mathrm{EU}+T) .
$$

Merchants advertising captivating "Hook" images need to develop and maintain a trust that the product collection pages they create are well curated and are reflective of what the "Hook" images advertise to maintain a positive experience for consumers.

To put the marketing strategy to test, we developed DoBundle, an online tool designed to make the process of product assembly simple, efficient, and easy to use. The tool implements the proposed marketing strategy allowing merchants to post a "Hook" image on social network sites that links to an intermediate page showcasing products related to the image. The tool has been carefully designed to comply with the criteria of the EWAM model. Figure 1 illustrates the factors that we considered in developing the tool to promote a positive $\delta$.

\section{Methods}

The previous section outlined a motivation for a marketing strategy that involves the advertising of a "Hook" image that links to a product collection page to increase e-commerce prospects. In this section, we describe an implementation of this strategy and present our digital method to assemble product collections and associate "Hook" images with them. As the tool is intended to be used by merchants, online stores, marketers, and influencers to create content for consumers, we have paid particular attention to automating the process of product data collection. Figure 2 provides a flowchart describing the method. We will also describe how we recruited marketers and influencers to use the tool and create product pages for consumers on social networks.

\subsection{Assembling Product Collection Pages}

4.1.1. Requirements. For the process outlined in this section to make sense, a user (online store) will have to perform a few simple tasks in the order they are presented in this section. We will assume that the online store has an online account on our website (http://dobundle.com) to perform the next steps. 


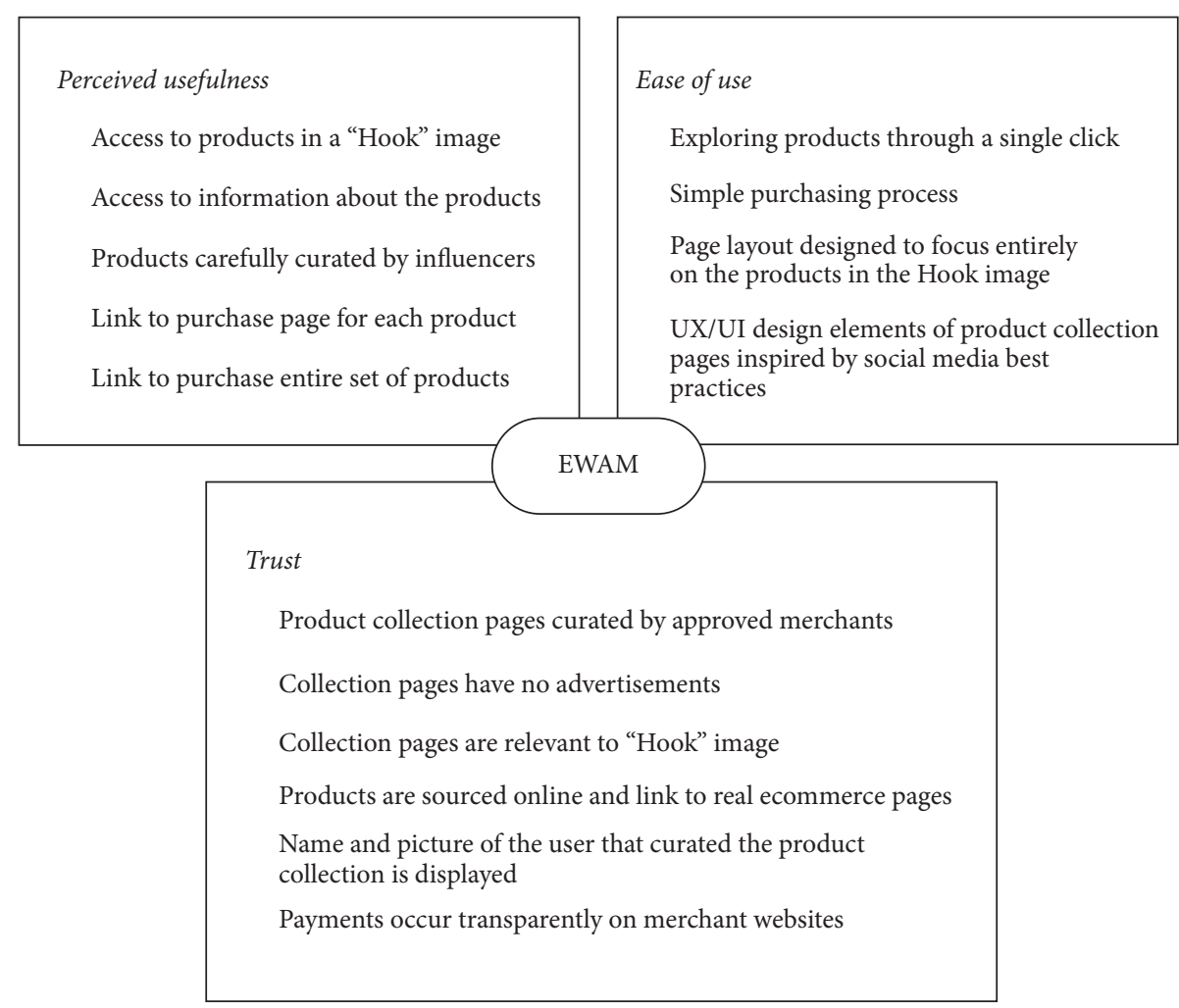

FIgURE 1: The application of the extended web assessment method criteria in the development of the DoBundle tool.

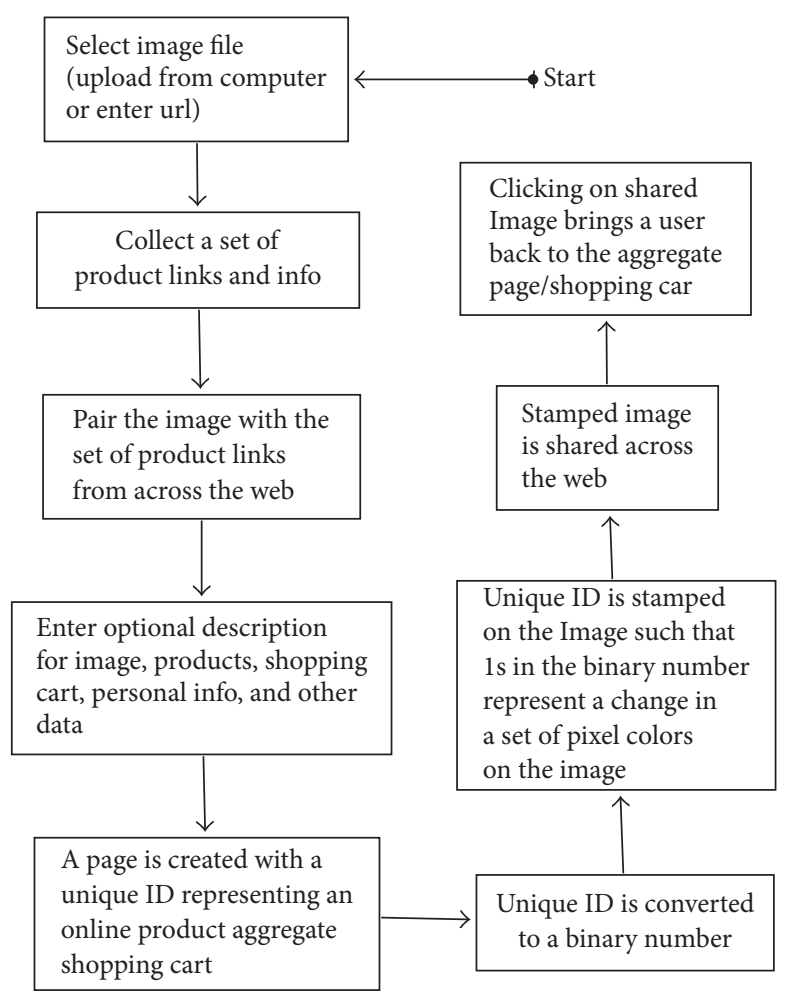

FIGURE 2: Procedure describing the assembly of product collections and associating them with a "Hook" image. 


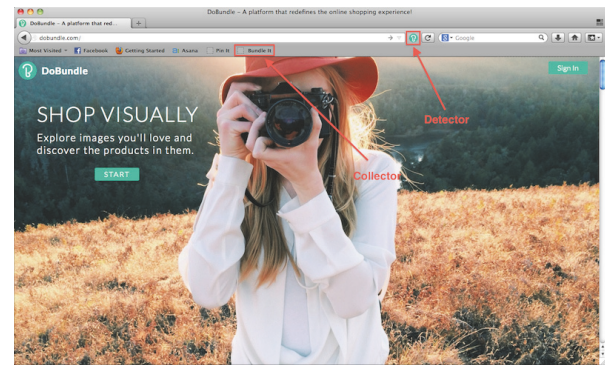

Figure 3: Product collector bookmarklet on a user's browser.

The online store will also have downloaded a "Collector" bookmarklet, as shown in Figure 3.

Step 1 (selecting a "Hook" image). After signing into their account, an online store starts the process by either uploading an image from their computer device or inputting the URL of an image online as presented in Figure 4.

Step 2 (collecting e-commerce products). A online store user surfs the web to create a product collection and match it to the "Hook" image they chose. They would typically select all the products from their online store. In our case, we will show the collection of 6 products from amazon.com in Figures 5 and 6. In Figure 5(a), a user surfs to the URL of the first product they want to capture and collect. Once they are on the product page, the user clicks on the "Bundle It" bookmarklet to capture product information off the page. The bookmarklet shows a side panel on the right of the page informing the user that information for the product will be captured and sent to their account. The side panel is shown in Figure 5(b), and sending the information is displayed in Figure 5(c). Once the information is sent, the user can go back to their account page and view the product that they just collected (see Figure 5(d)). The "Bookmarklet" automatically collects a product's title, image source, price, description, and page URL. The user then collects 5 more products (not shown). When they are done, they visit their account page again and find the 6 products they collected, as shown in Figure 6.

Step 3 (matching a Hook image to the product collection). A online store user goes back to their account and matches the image they chose to the products they collected. Hovering over a product brings out an add/remove element. Clicking on a product matches it to the "Hook" lead image, as shown in Figure 7(a). The user continues matching products to their image resulting in a collection, or "bundle", of 6 products (Figure 7(b)).

Step 4 (publishing the "Hook" image and product collection). In this step the online store user enters some more information about the content they are creating. They add a Title, Description, and a few other fields. Clicking "Publish" on Figure 8 will create a product collection page that contains the selected products' images, links, descriptions, titles, and prices. This page will include a unique id in its URL in the form: "http://dobundle.com/shop-ID". The ID in our implementation is an integer number and is explained further in the next section.

Step 5 (stamping the image with an OPCI). Online stores and marketers post images on the Internet with an embedded link back to e-commerce product pages, e-commerce shopping cart pages, or in our case product collection pages. To avoid the loss of links as images are shared and distributed over the Internet, our technology stamps "Hook" images with a novel Online Product Collection Identifier (OPCI) that can be linked back to the original product collection source pages. The OPCI is engrained in the pixels of the photo, allowing for the permanent association between the "Hook" image and its prepopulated product collection page.

A representative sample image that the online store can choose is displayed in Figure 9(a). We take this image and produce the exact same copy with a stamp that includes a "plus" sign and a binary OPCI encoded in the pixels of the stamp. The use can choose the stamp to be round or square.

Each stamp generates a unique decimal OPCI to include in the product collection link. The decimal OPCI is converted into a binary number of 64 digits. The 64 digits are encoded into the stamp's pixels. We encode the 64 digits into 64 components in the stamp, each component (square of pixels) stores the value of 1 binary digit. The $1 \mathrm{~s}$ correspond to a change of color in the component, in our case, "brighter" spots. 0s will not change the pixel colors in the component. The final sample output is presented in Figure 9(b). We provide a detailed description of the method used to create OPCI stamps in Supplementary Material available online at https://doi.org/10.1155/2017/9264920. Figures S1 and S2 in Supplementary Material provide a blueprint composition of these stamps and discuss a protocol for detecting the stamps.

4.2. Recruitment of Content Creators. The DoBundle tool was advertised on social platforms such as Facebook and Twitter and targeted online store owners, influencers, and blogger content curators to construct "Hook" images that hyperlink to multiproduct collection pages. The online news network, TechCrunch, advertised DoBundle to their technology enthusiastic user base. In addition, we contacted 45 bloggers and small online store owners to create collections of products for their audiences.

4.3. Sharing the Hook Images and Product Collection Pages. After the "Hook" image is stamped, the DoBundle content curator is redirected to their product collection page shown in Figure 10. This page has a unique URL that contains the OPCI in decimal format. The online store can now share this page on social network platforms and blogs across the Internet. To share, they click on one of the sharing buttons on the page. The buttons pick up the stamped image and the page URL and shares them as representatives of the product collection page. In Figure 11, we show the result of clicking on a Pinterest share button. The stamped image is picked up as the product collection representative image.

4.4. Extended Web Assessment Method. The EWAM emphasizes that successful e-commerce websites should take into 


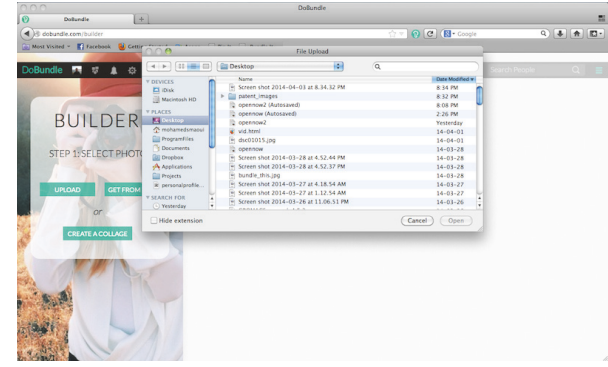

(a)

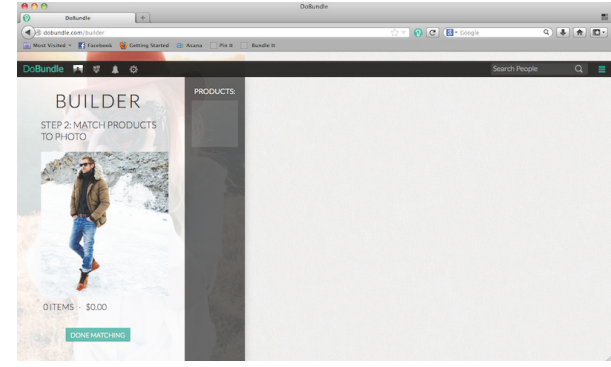

(b)

FIGURE 4: Selecting a "Hook" image. (a) A online store can upload a photo from their computer or include a link to the image if it is on the web. (b) After a user selects an image, it is displayed on their screen.

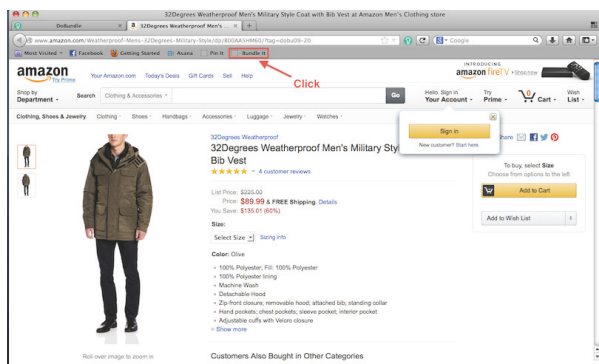

(a)

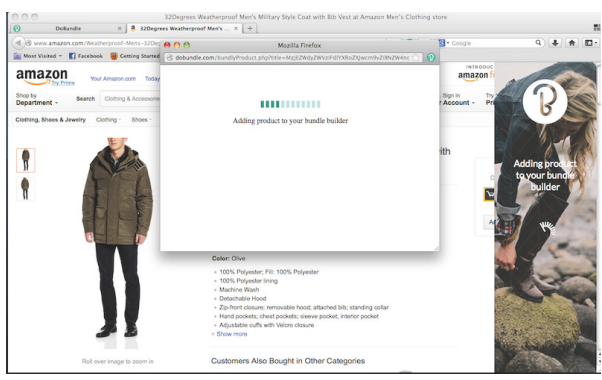

(c)

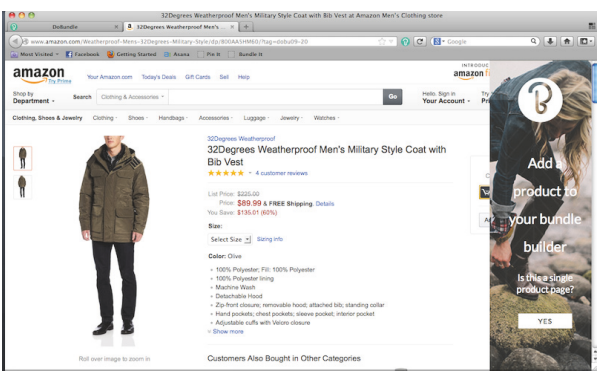

(b)

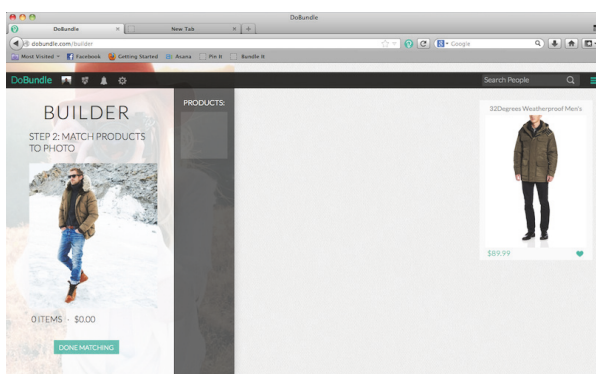

(d)

FIgURE 5: Collecting an online product. (a) User surfs to the URL of the first product they want to match with their image; (b) user clicks on the "Bundle It" bookmarklet. It shows a side panel to fetch the product information; (c) product information is sent to the user's online account; and (d) product appears on the user's account page.

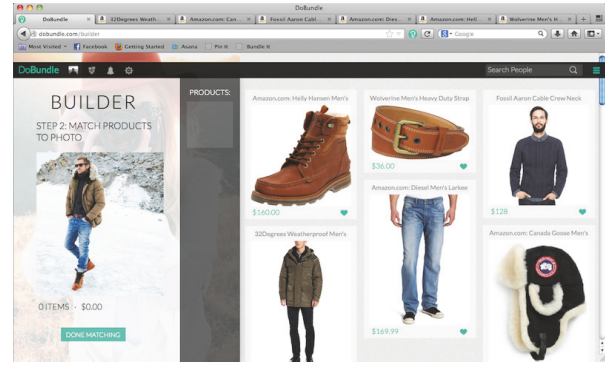

FIGURE 6: Online store's account page with all 6 collected products.

account elements that increase "perceived usefulness," "ease of use," and "trust" to the consumer. In addition, websites not only should sell a core product on their transaction page but should also offer a range of complimentary products to maximize customer benefit. The additional products add to the perception of usefulness and attractiveness to the consumer. The product collection pages have been carefully designed to showcase all the products to the consumer in an aesthetic and functional manner similar to websites such as Pinterest and Tumblr. The idea of clustering the products inside a "Hook" image in one location and providing links to their sources contributes to the perceived usefulness of the site. In terms of ease of use, a product collection page only provides basic information about the products and links to the pages where a purchasing transaction can occur. Moreover, online stores can enable the feature of a "Purchase All" button that allows a consumer to purchase all the items of a collection page in 1 click over a secure channel. 


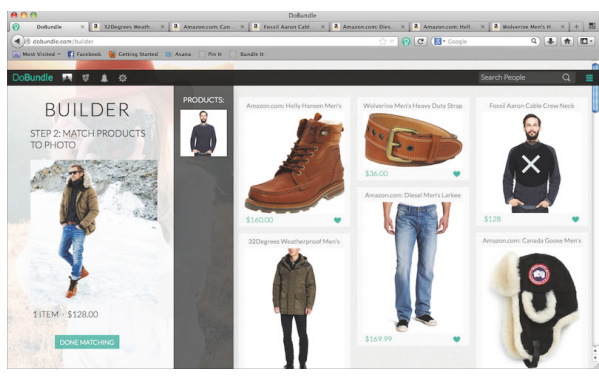

(a)

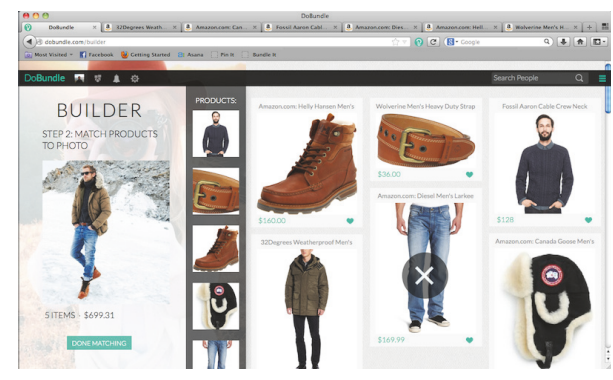

(b)

FIGURE 7: Associating products with Hook photo. (a) User matching 1st product to their image. (b) User matching 6th product to their image.

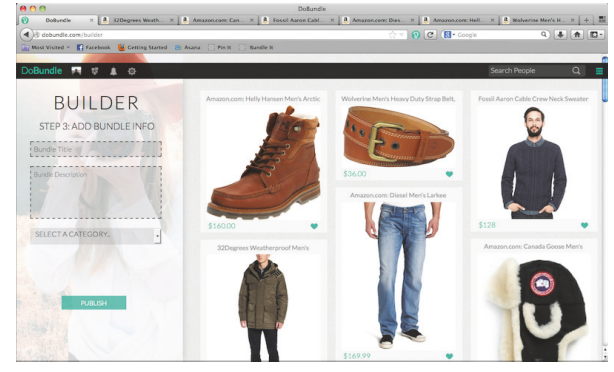

Figure 8: Last step before publishing a user's "Hook" image and product collection page.

4.5. Analytics. To collect usage data points and the metrics for DoBundle, we used Google Analytics (http:/google.com/ analytics) and StatHat (http://www.stathat.com/) services. Google Analytics collected data pertaining to consumer demographics, characteristics, social sources and page view data. StatHat was used to keep track of statistics such as the number of visits to product collection pages, number of "Hook" images, views, impressions, and consumer action data.

\section{Results and Discussion}

We outlined in the previous section the DoBundle tool for online stores to create product collection pages and represent the product collections with specially tagged "Hook" images that can be shared on social networks. Particular emphasis was placed on the elements contributing to the ease of use of the tool. In this section, we aim to use the tool to investigate answers to our main question: "how can online stores increase the purchasing prospects of their products with images they use on social networks?" In Section 3, we provided a theoretical motivation to how product collection pages can increase purchasing prospects and influence customer purchasing behavioral intentions. We present in this section data pertaining to the current use of the DoBundle tool, the type of "Hook" images that online stores and content curators designed, the reaction of social network consumers to the "Hook" images, and sales conversion metrics of multiproduct collection pages.
5.1. Content Creators. As outlined in Methods, we recruited e-commerce content creators (online stores, bloggers, influencers) from social network sites and blogs. We also sent a request to TechCrunch to advertise the tool to its user base for additional exposure to help generate data for this study. We received 1426 user registrations on our site, from which only 125 created collections and "Hook" images. We hypothesize that the majority of users who did not create a collection do not identify as content creators or online stores but rather as consumers. The 125 users made 1108 product collections from a range of 12,510 user collected products online. The average size of a product collection was 6.5 products per collection. The content creators shared the respective "Hook" images on their various social networks through the share widget on the product collection pages. None of the users were financially solicited to create content.

5.2. Hook Image Types. Figure 12 displays the four types of "Hook" images that content creators on our site created for marketing their collections. The first type is a simple photo containing images of the collection products placed together in the form of a bundle or collage (see Figure 12(a)). These types of "Hook" photos market the entire products of the collection under a grouping theme. The second type of "Hook" image is what we call a landscape photo, as shown in Figure 12(b). This type of photo provides viewers an idea of what the product collection is about. The products are generally not shown in the photo but are directly related to the theme of the image. Figure 13(b) presents the product collection that is associated with this landscape "Hook" image. The third type of image (Figure 12(c)) is a model/lifestyle "Hook" image aimed at marketing the products that a model is wearing or interacting with. The last type of "Hook" image is a single product image. Online stores and content creators who do not need to create a multiproduct collection page have used this option. On the DoBundle platform, we categorized the "Hook" images that users have created into 11 subcategories that included fashion, entertainment, books, technology, and health.

Table 1 portrays the traffic data we collected from consumers visiting from social networks. The column, Hook image type, lists the four types of images that online stores and curators shared on social networks along with their 
TABLE 1: Consumer clicks on Hook images from social networks.

\begin{tabular}{lccc}
\hline Hook image type & Distribution (\%) & Social network traffic (\%) & Normalized traffic (\%) \\
\hline Single product & 10 & 2.72 & 6.80 \\
Landscape & 30 & 12.73 & 10.61 \\
Model & 40 & 36.59 & 22.87 \\
Collage & 20 & 47.96 & 59.95 \\
\hline
\end{tabular}

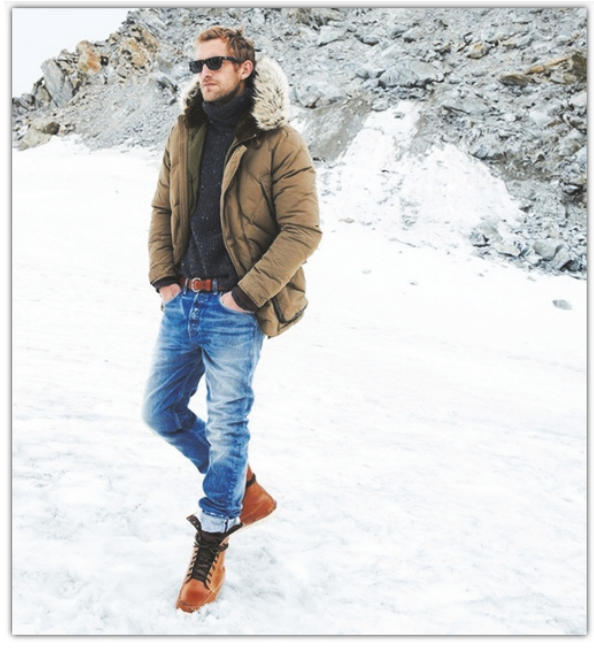

(a)

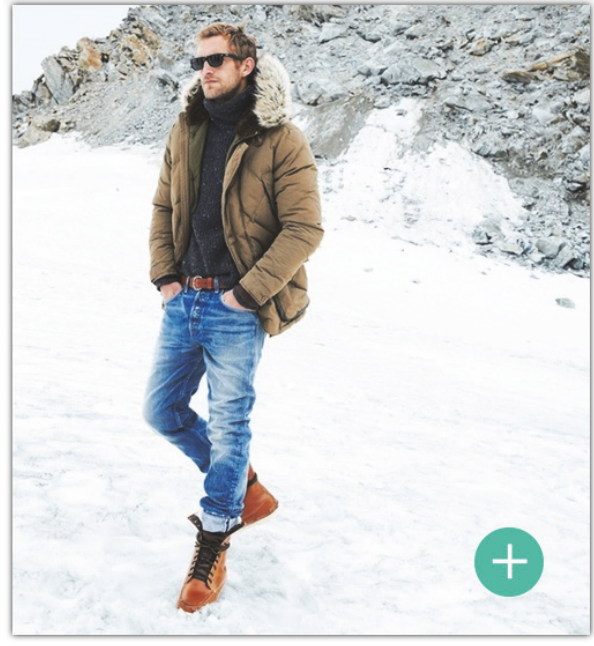

(b)

FIGURE 9: Stamping "Hook" photo. (a) The image a user wants to pair with products and (b) the same image stamped and encoded with an OPCI.

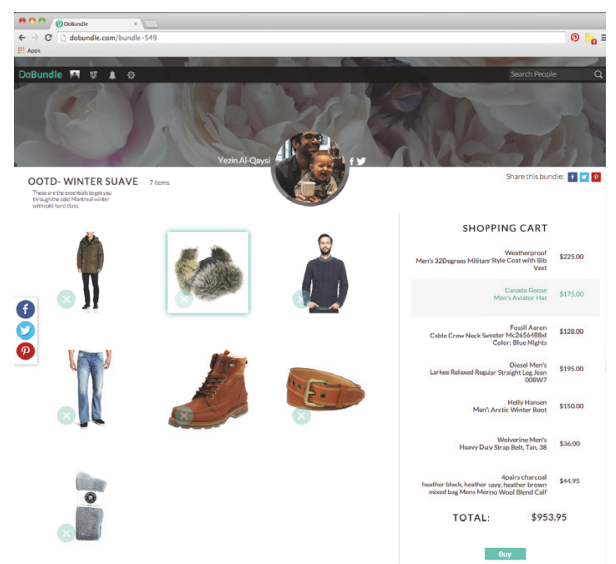

FIGURE 10: A snapshot of what a product collection page looks like. The page stores the products online store user has matched to their photo, a cart section, the online store's info, and links to more collections created by the store.

distributions. For example, only $10 \%$ of Hook images shared on social networks by content creators were single product images. The social network traffic column describes the percentage of clicks with each image type. The collage type Hook images received more than forty-five percent of all consumer clicks on social networks. The results in this table suggest that consumers are three times more likely to click on

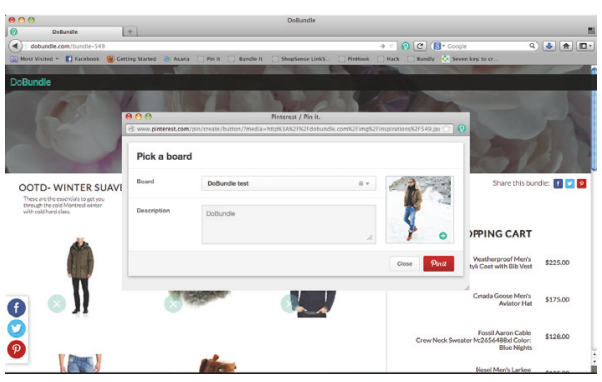

FIGURE 11: A screenshot of Pinterest pulling the stamped image to share on its platform.

a collage "Hook" image than they would for a single product type post. The behavioral intentions to click on the image influenced by attitudes and subjective norms appeared to be highest with collage "Hook" images.

5.3. Attitudes towards Multiproduct Pages. We report in this section the results obtained from consumers who clicked on the "Hook" images that were shared on social networks. The consumers clicked on the images (see Table 1) to find themselves redirected to the DoBundle product landing pages. We report in Table 2 the data we collected at this stage.

We received more than 180,000 visits to the 1108 product collection pages. Traffic sources included consumers 


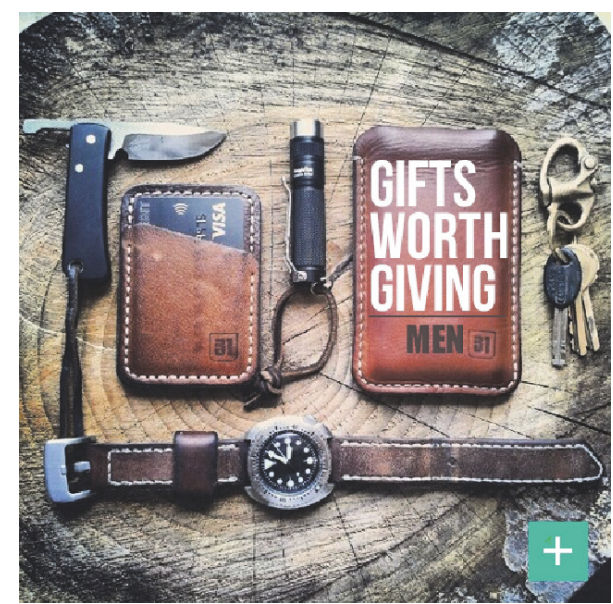

(a) Collage/bundle

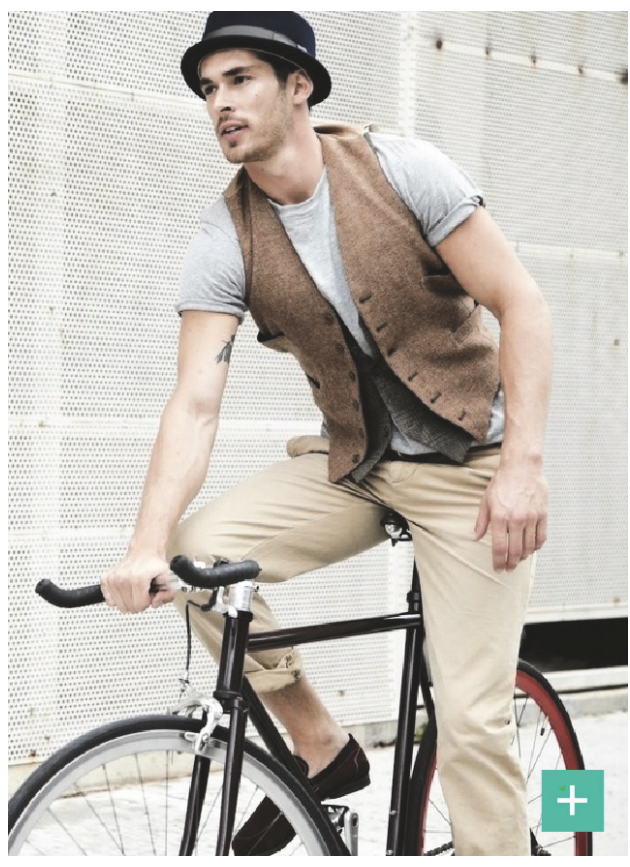

(c) Model

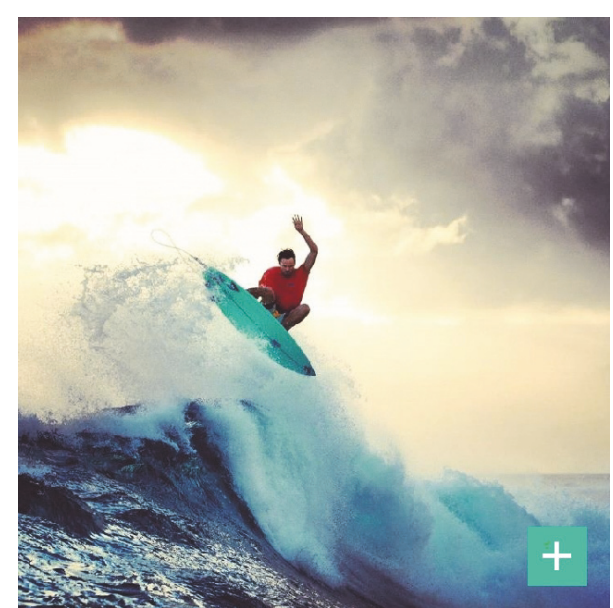

(b) Landscape

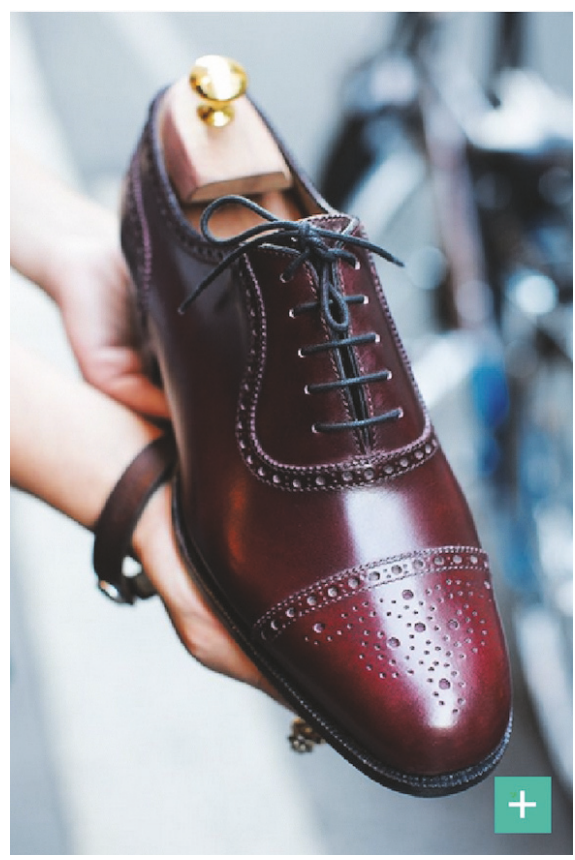

(d) Single product

FIGURE 12: Different types of possible Hook photos.

TABLE 2: Platform statistics during 2014-2015.

\begin{tabular}{lc}
\hline Number of & Value \\
\hline Hook images impressions & 930,657 \\
Product collection views & 183,320 \\
Purchases pursued & 9052 \\
\hline
\end{tabular}

from Facebook, Pinterest, Instagram, Twitter, Google Images, Polyvore, and many blogs (see Figure 14).

Table 3 and Figure 15 present our visitors' demographics, age, gender, and commerce interest. About two-thirds of the consumers were females aged 18-34. The top consumer interests were in the categories of entertainment, technology, fashion, and home decor. We experienced a relatively high bounce rate (approx. 30\%) from nonsocial channels such as search engines. Bounce rate is the number of visits in which a consumer left the website from the initial landing page without browsing any further. Table 4 includes a breakdown of the average viewing duration times of the product collection pages.

The conversion rate (purchases pursued/product collection views) from the product collection pages to purchasing action was a high $4.94 \%$ compared to the average $0.2 \%-2 \%$ on e-commerce stores $[33,34]$. Consumers visiting the product collection pages clicked on more than one product. A small number of consumers were interested in purchasing all the products in the collection through clicking the "Buy All" button that was enabled on pages that contained products from a single online store (e.g., Amazon; data not reported). On 


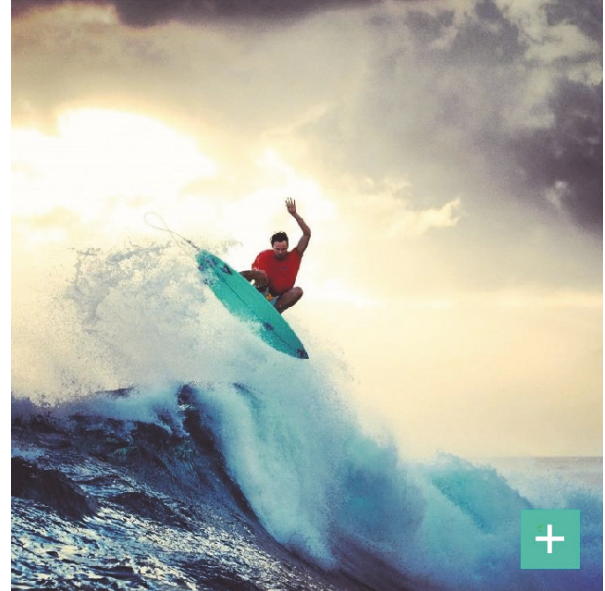

(a) Hook image
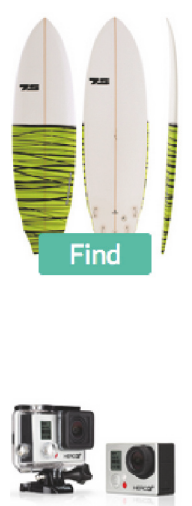

Find
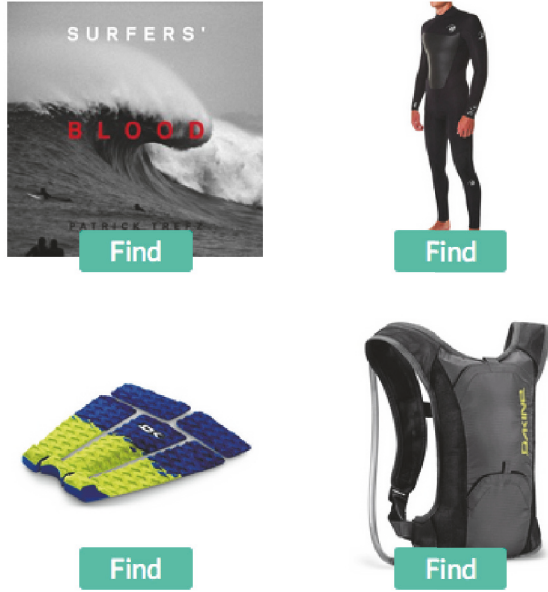

(b) Intermediate multiproduct collection page

Figure 13: Products of a sample landscape Hook image. Clicking on the Hook image (a) from social network platforms directs consumers to (b) an intermediate page with several products to explore.

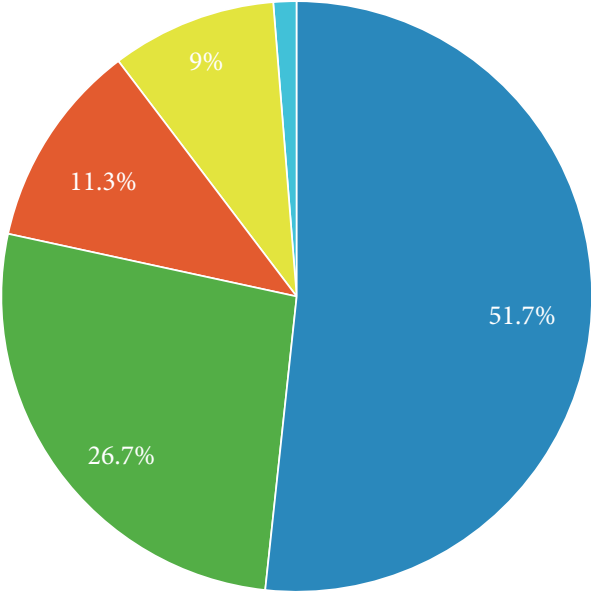
Social
Direct
Organic search

Referral
(Not set)
(Other)

(a) Consumer sources

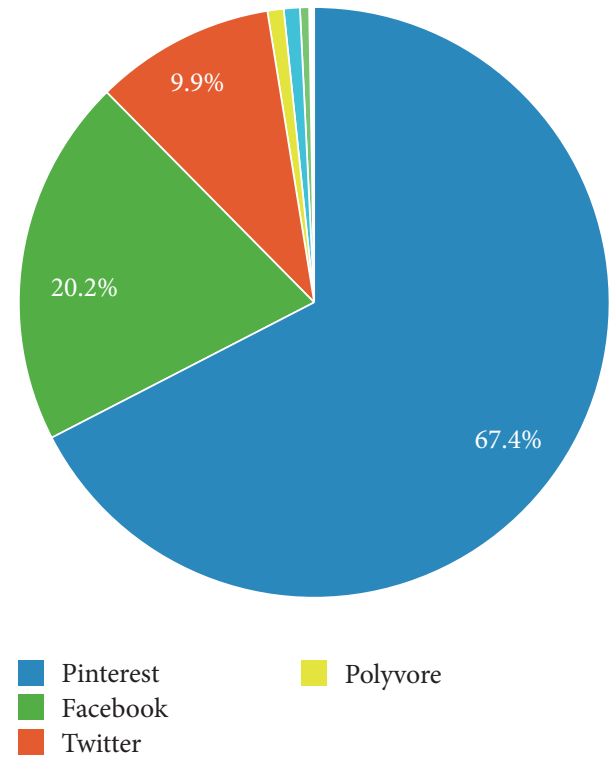

(b) Social sources

FIgURE 14: Traffic sources to the product collection pages.

the bottom section of each product collection page, we added three additional random "Hook" images that a consumer could click on to explore other collections, as inspired by the EWAM criteria. This strategy enabled consumers to view an additional 197,000 "Hook" image impressions on the website's main scrolling page. Once consumers found that a "Hook" image leads them to a product collection page, they continued to explore more "Hook" photos and product collections on the site.

The results of this study suggest that online stores can increase the purchasing prospects of their products if they market the products within a collection and advertise the collection on social networks with collage type "Hook" images.
Posting a single "Hook" image instead of 3-6 product images on social networks improves diffusion of traffic and achieves a better targeted marketing strategy. Since the factors that affect TRA and TPB behavioral intention include attitude and subjective norms, online stores that pay particular attention to designing "Hook" images that are visually appealing, designed as a collage of products, culturally appropriate, and segmentally differentiated to their specific consumer base should result in positive consumer attitudes and favorable subjective norms. In turn, this will affect behavior of examining products and purchasing prospects.

The DoBundle tool has facilitated a process that shed light on the e-commerce potential of a new marketing 


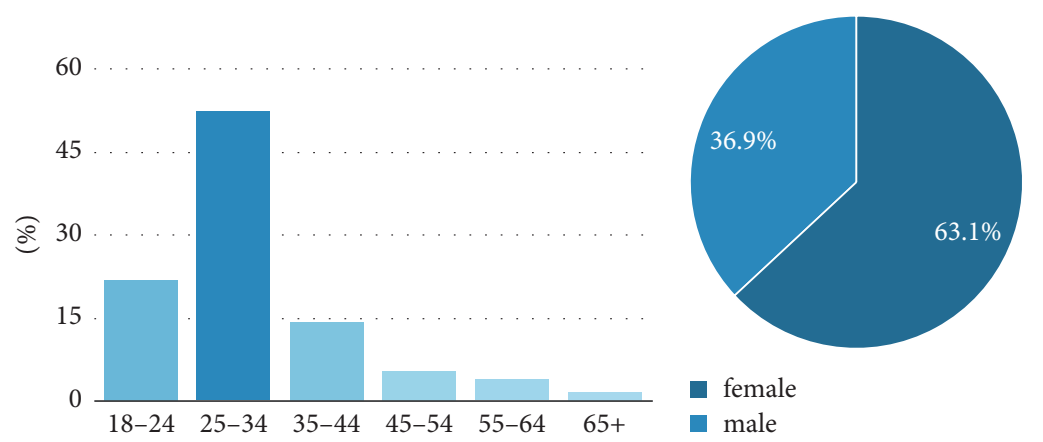

(a) Age

(b) Gender

$\begin{array}{ll}5.71 \% & \text { Movie Lovers } \\ 5.47 \% & \text { Technophiles } \\ 5.21 \% & \text { Shoppers/Shopaholics } \\ 5.09 \% & \text { TV Lovers } \\ 4.86 \% & \text { Shutterbugs } \\ 3.78 \% & \text { Cooking Enthusiasts/Aspiring Chefs } \\ 3.58 \% & \text { Home Decor Enthusiasts } \\ 3.42 \% & \text { News Junkies \& Avid Readers } \\ 3.37 \% & \text { News Junkies \& Avid Readers/Entertainment \& } \\ 3.34 \% & \text { Celebrity News Junkies } \\ & \text { Music Lovers }\end{array}$

(c) Affinity category

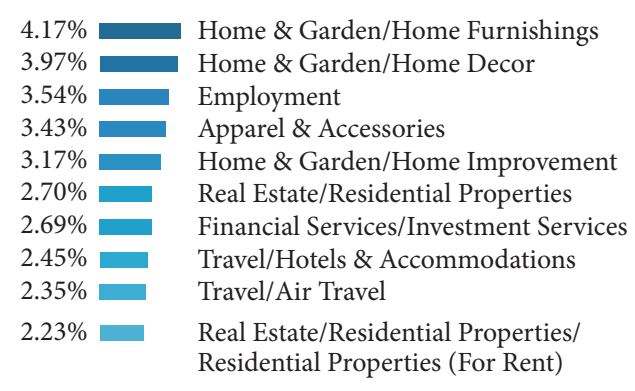

(d) In-market segment

FIGURE 15: Consumer demographics.

TABLE 3: Geography of consumers in study.

\begin{tabular}{lc}
\hline Country & Percentage of page views \\
\hline Canada & 57.62 \\
United States & 25.22 \\
United Arab Emirates & 2.74 \\
United Kingdom & 2.08 \\
Saudi Arabia & 1.30 \\
France & 0.81 \\
Jordan & 0.81 \\
India & 0.65 \\
Mexico & 0.50 \\
Brazil & 0.45 \\
Other & 7.83 \\
\hline
\end{tabular}

TABLE 4: Duration of multiproduct page views.

\begin{tabular}{lc}
\hline Page view duration & Percentage \\
\hline $0-10$ seconds & 30.98 \\
$11-30$ seconds & 4.58 \\
$31-60$ seconds & 5.63 \\
$61-180$ seconds & 11.04 \\
$181-600$ seconds & 12.39 \\
$601-1800$ seconds & 13.30 \\
$1801+$ seconds & 22.08 \\
\hline
\end{tabular}

strategy. The strategy suggested a higher click-through rate on product images if products were grouped together by "theme" and marketed as a whole. Other tools can be utilized to explore this strategy and further quantify the purchasing prospects of users interacting with "Hook" images. Shopping platforms such as Shopify (https://www.shopify.com), WP eCommerce (https://www.wpecommerce.org), and Squarespace (https://www.squarespace.com) are avenues that can further explore our findings. These platforms can examine user behavior and shopping intent using constructs such as shopping cart abandonment, purchasing cycle, and clickthrough rates. Integrated with DoBundle and social networks, these platforms can further quantify the effectiveness of the product collection landing pages starting from a site such as Facebook and ending with a sale transaction.

5.4. Online Product Collection Identifiers. The "Hook" images used on DoBundle were stamped with a novel OPCI for two main reasons. First, the OPCI visual marker is intended to make consumers aware that there is additional content following the clicking of the image, influencing and shaping an "attitude" towards these shoppable images. Second, the OPCI engrains a binary digit into the pixels of the image allowing for the reconstruction of the hyperlink joining the "Hook" image with the product collection page if it were ever lost due to social network sharing issues. Platforms such as Google Images, Pinterest, and Facebook can decode the OPCI from stamped images to build and correct their links.

Unlike the mobile quick response (QR) codes [35] that have been increasingly used in cross-media advertising campaigns, the OPCI is designed to provide a visual shopping cue for consumers to click on and learn more about the products they see in an image. The OPCIs have been aesthetically and structurally designed for e-commerce and as a strategy to attract consumer engagement with product collections. 
Moreover, they allow for the task of building rot links around e-commerce images across social networks and the Internet.

\section{Conclusion}

Through the DoBundle tool that we built, we first explore the different types of product images that online stores, marketers, and influencers create for consumers on social networks. Second, we compare the click-through rate level of consumers on social networks with these different image types. Furthermore, we investigate the engagement of consumers with e-commerce purchase pages hyperlinked from a clicked image on a social network. We design these purchase pages with multiple product offerings to stimulate the factors of consumer convenience, ease of use, perceived usefulness, interactivity, depth of information, targeted marketing, and social endorsement.

In order to conduct this study and assess the persuasion of different types of e-commerce images on consumer engagement, we outlined in this paper the development of a software method to assemble a product collection and represent it with a "Hook" image. The image, stamped with a distinct representation identifying it as an online product collection lead, links back to a prepopulated product collection page. The page contains data pertaining to the products in the lead image or the theme motivated by the lead image. The stamp on the image contains a unique Online Product Collection Identifier (OPCI) engrained in the pixels of the photo, allowing for the permanent association between the lead image and its prepopulated product collection page. The stamped image is saved to the storage disks of a server in a public read-only location, allowing it to be shared and viewed by third-party sharing services.

Our study concludes that consumers on social networks are more likely to engage with e-commerce images that portray a collage/bundle of products. In our study, normal single product images received a $6.8 \%$ click-through rate. These images were just like any product image that a merchant would currently normally post to their users. The other types of "Hook" images that were shared on social media (collage, landscape, and model) received significantly more engagement that translated to higher click-through rates $(10 \%-60 \%)$. Collaged images accounted for $60 \%$ of all traffic from social network sites. This translates to an increase in the value of $\delta$ in (8) of Model 2 and increased $\Delta X$ revenue in (19). In addition, to capitalize on consumer interest and commerce opportunity, these collaged images should link to a multiproduct collection page. Once on these pages, consumers in our study explored the collection of related products. We recorded a purchasing click rate of $4.94 \%$ on these pages, compared to the expected market $2 \%$. The effect of increased purchasing click rate values are modelled in (20) and reflect an increase in revenue of $\Delta Y$ (see (21)) proportional to the increase in click rates. Overall, the proposed marketing strategy presented a significantly increased e-commerce potential.

Collaged image posts on social networks that are presented to consumers through social influences have higher purchasing prospects for online stores. A social influencer can be member of a consumer's circle of friends, family, following, or personal favorite celebrities. Subjective norms are affected by social influences and a consumer's perceived popularity of a post. A post's likes, shares, recommendations, tweets, pins, and comments all influence a consumer's behavioral intention.

\section{Future Work}

Consumers on social networks are easily able to share ecommerce images that they have discovered with other consumers who are part of their network. This process of sharing and resharing enables a rapid and widespread communication of images which is almost viral in fashion [36]. Online stores have recognized the popularity of this practice among consumers and have leveraged the situation by designing various kinds of "Hook" images on their social pages. Images that they share can be associated with links that direct a consumer who discovers the image back to the store's webpage [37]. While this is a very effective method to gain recognition and to generate sales on the Internet, there is a serious flaw which hinders its potential substantially. The process of resharing results in the image owner losing control of the image they shared. This means that if an image is shared with a link pointing to the store's website, this link can be lost when the image is subsequently reshared by other consumers and posted on different networks and platforms, as also researched and explained by several research articles $[38,39]$. A consumer resharing the image can also edit it to link back to their own website, effectively depriving the store of traffic that could have been directed to their store. The consumer can additionally edit the image with irrelevant content that can affect an online store's reputation. These edits and the loss of the picture's original link are further problematic for potential buyers. A consumer who discovers a product's image would expect that clicking on the image would direct them to a website associated with the product. If this links were changed, removed, or lost when the picture was reshared, this would frustrate the consumer and make it far more difficult for him or her to find the picture's original source.

We plan to address the issues presented above in a future manuscript detailing an algorithm that decodes the OPCI stamp on "Hook" images and reconstructs incorrect or missing hyperlinks. The algorithm will be packaged into a browser plugin that automatically checks images on web pages for the OPCI stamp, decodes the stamp, and validates the hyperlink on the "Hook" images. Incorrect links can be fixed, missing links can be reconstructed with an anchor html tag, and modified "Hook" images can be replaced with their original versions. In addition, if an online store decides to discontinue a product collection, the algorithm can disable the link on the "Hook" image and replace the image with its original nonstamped version.

The future algorithm should also take into account issues pertaining to search engines that can index these "Hook" images off the DoBundle site or social network platforms. If the images contain incorrect or missing links on the web, the search engines will store invalid links. The ultimate solution 
to this problem would be for the search engines to rely on the detector plugin's technology to correct their links. Since this would require adoption from engines such as Google, Yahoo, and Bing, without huge market adoption this solution might be far-fetched in the near future. However, a normal consumer browsing image search results could have their detector plugin fix all the incorrect links.

\section{Data Access}

DoBundle is available as a web service technology at http:// dobundle.com.

\section{Conflicts of Interest}

The author declares that there are no conflicts of interest regarding the publication of this paper.

\section{Acknowledgments}

This work has been supported by the DoBundle team. Special thanks are due to Mr. Yezin Al-Qaysi, Ms. Dina Al-Qaysi, and Ms. Dima Al-Ashram for taking part in the conception, design, and creation of the DoBundle tool.

\section{References}

[1] X. Liu, W. Wang, and L. Zhang, "The mechanism analysis of the impact of Ecommerce to the changing of economic growth mode," in Proceedings of the 2012 IEEE Symposium on Robotics and Applications, ISRA 2012, pp. 698-700, Kuala Lumpur, Malaysia, June 2012.

[2] D. Van den Poel and W. Buckinx, "Predicting online-purchasing behaviour," European Journal of Operational Research, vol. 166, no. 2, pp. 557-575, 2005.

[3] M. Tohidi and A. Warr, "The bigger picture: The use of mobile photos in shopping," Lecture Notes in Computer Science (including subseries Lecture Notes in Artificial Intelligence and Lecture Notes in Bioinformatics): Preface, vol. 8120, no. 4, pp. 764-771, 2013.

[4] W. Di, N. Sundaresan, R. Piramuthu, and A. Bhardwaj, "Is a picture really worth a thousand words? - On the role of images in e-commerce," in Proceedings of the 7th ACM International Conference on Web Search and Data Mining, WSDM 2014, pp. 633-641, New York, NY, USA, February 2014.

[5] M. Duffy, "Microblogging: Tumblr and pinterest," American Journal of Nursing, vol. 113, no. 6, pp. 61-64, 2013.

[6] C. Palacios-González, "The ethics of clinical photography and social media," Medicine, Health Care and Philosophy, vol. 18, no. 1, pp. 63-70, 2015.

[7] Y. Chang, L. Tang, Y. Inagaki, and Y. Liu, "What is Tumblr," $A C M$ SIGKDD Explorations Newsletter, vol. 16, no. 1, pp. 21-29, 2014.

[8] M. A. Hodis, R. Sriramachandramurthy, and H. C. Sashittal, "Interact with me on my terms: a four segment Facebook engagement framework for marketers," Journal of Marketing Management, vol. 31, no. 11-12, pp. 1255-1284, 2015.

[9] L. Hasan, A. Morris, and S. Probets, "Using google analytics to evaluate the usability of e-commerce sites," Lecture Notes in Computer Science (including subseries Lecture Notes in Artificial Intelligence and Lecture Notes in Bioinformatics): Preface, vol. 5619, pp. 697-706, 2009.
[10] M. Fishbein and I. Ajzen, Belief, attitude, intention, and behavior: an introduction to theory and research, Addison-Wesley Pub. Co, Reading, Mass, USA, 1975.

[11] I. Ajzen, From Intentions to Actions: A Theory of Planned Behavior, Action control, 1985.

[12] T.-P. Liang and E. Turban, "Introduction to the special issue social commerce: A research framework for social commerce," International Journal of Electronic Commerce, vol. 16, no. 2, pp. 5-13, 2011.

[13] C. Aubrey and D. Judge, "Re-imagine retail: Why store innovation is key to a brands growth in the, new normal, digitallyconnected and transparent world," Journal of brand strategy, vol. 1, no. 1, pp. 31-39, 2012.

[14] W. Winn and K. Beck, "The persuasive power of design elements on an e-commerce Web site," Technical Communication, vol. 49, no. 1, pp. 17-35, 2002.

[15] T. Saari, N. Ravaja, J. Laarni, M. Turpeinen, and K. Kallinen, "Psychologically targeted persuasive advertising and product information in e-commerce," in Proceedings of the 6th International Conference on Electronic Commerce, ICEC04, pp. 245254, Delft, The Netherlands, October 2004.

[16] M. Kim and S. Lennon, "The effects of visual and verbal information on attitudes and purchase intentions in internet shopping," Psychology \& Marketing, vol. 25, no. 2, pp. 146-178, 2008.

[17] R. Asunmaa, Perceptions of Convenience, Risk and Enjoyment in Online Shopping, University of Jyvaskyla.

[18] M. K. Chang, "Predicting unethical behavior: A comparison of the theory of reasoned action and the theory of planned behavior," Journal of Business Ethics, vol. 17, no. 16, pp. 18251834, 1998.

[19] A. Bandura, "Self-efficacy: toward a unifying theory of behavioral change," Psychological Review, vol. 84, no. 2, pp. 191-215, 1977.

[20] B. H. Sheppard, J. Hartwick, and P. R. Warshaw, "The theory of reasoned action: a meta-analysis of past research with recommendations for modifications and future research," Journal of Consumer Research, vol. 15, no. 3, pp. 325-345, 1988.

[21] L. Jiang, Z. Yang, and M. Jun, "Measuring consumer perceptions of online shopping convenience," Journal of Service Management, vol. 24, no. 2, pp. 191-214, 2013.

[22] A. Bhatnagar and S. Ghose, "Segmenting consumers based on the benefits and risks of Internet shopping," Journal of Business Research, vol. 57, no. 12, pp. 1352-1360, 2004.

[23] M. Bednarz and N. Ponder, "Perceptions of retail convenience for in-store and online shoppers," Marketing Management Journal, pp. 49-65, 2010.

[24] P. Schubert, "Extended web assessment method (EWAM): Evaluation of electronic commerce applications from the customer's viewpoint," International Journal of Electronic Commerce, vol. 7, no. 2, pp. 51-80, 2003.

[25] H. H. Kuan, G.-W. Bock, and V. Vathanophas, "Comparing the effects of usability on customer conversion and retention at ecommerce websites," in Proceedings of the 38th Annual Hawaii International Conference on System Sciences, p. 174, Big Island, HI, USA, January 2005.

[26] M. I. Eid, "Determinants of e-commerce customer satisfaction, trust, and loyalty in Saudi Arabia," Journal of Electronic Commerce Research, vol. 12, no. 1, pp. 78-93, 2011.

[27] M. Jun, Z. Yang, and D. Kim, "Customers' perceptions of online retailing service quality and their satisfaction," International 
Journal of Quality \& Reliability Management, vol. 21, no. 8, pp. 817-840, 2004.

[28] F. D. Davis Jr, A Technology Acceptance Model for Empirically Testing New End-User Information Systems: Theory and Results, Massachusetts Institute of Technology.

[29] P. Legris, J. Ingham, and P. Collerette, "Why do people use information technology? A critical review of the technology acceptance model," Information \& Management, vol. 40, no. 3, pp. 191-204, 2003.

[30] J. J. Garrett, The Elements of User Experience: User-Centered Design for The Web, New Riders, Indianapolis, Ind, USA, 1st edition, 2003.

[31] D. E. Rosen and E. Purinton, "Website design: Viewing the web as a cognitive landscape," Journal of Business Research, vol. 57, no. 7, pp. 787-794, 2004.

[32] K. Karvonen, "The beauty of simplicity," in Proceedings of the Conference on Universal Usability, pp. 85-90, November 2000.

[33] R. Olbrich and C. Holsing, "Modeling consumer purchasing behavior in social shopping communities with clickstream data," International Journal of Electronic Commerce, vol. 16, no. 2, pp. 15-40, 2011.

[34] D. G. Taylor and M. Levin, "Predicting mobile app usage for purchasing and information-sharing," International Journal of Retail \& Distribution Management, vol. 42, no. 8, pp. 759-774, 2014.

[35] M. B. Hoy, "An introduction to qr codes: linking libraries and mobile patrons," Medical Reference Services Quarterly, vol. 30, no. 3, pp. 295-300, 2011.

[36] B. J. Jansen, K. Sobel, and G. Cook, "Classifying ecommerce information sharing behaviour by youths on social networking sites," Journal of Information Science, vol. 37, no. 2, pp. 120-136, 2011.

[37] R. G. Curty and P. Zhang, "Social commerce: Looking back and forward," Proceedings of the ASIST Annual Meeting, vol. 48, no. 1, pp. 1-10, 2011.

[38] P. Burnhill, M. Mewissen, and R. Wincewicz, "Reference rot in scholarly statement: Threat and remedy," Insights, vol. 28, no. 2, pp. 55-61, 2015.

[39] M. Klein, H. Van De Sompel, R. Sanderson et al., "Scholarly context not found: One in five articles suffers from reference rot," PLoS ONE, vol. 9, no. 12, Article ID el15253, 2014. 


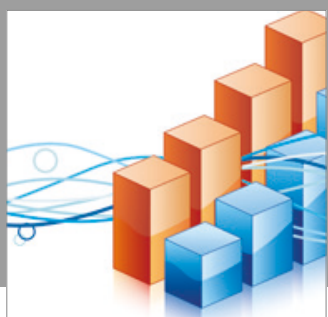

Advances in

Operations Research

vatersals

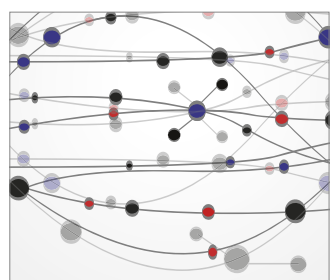

\section{The Scientific} World Journal
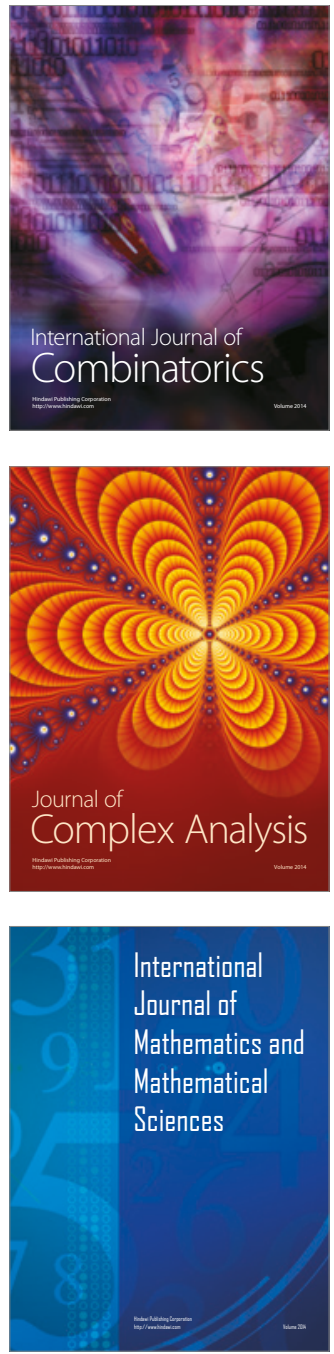
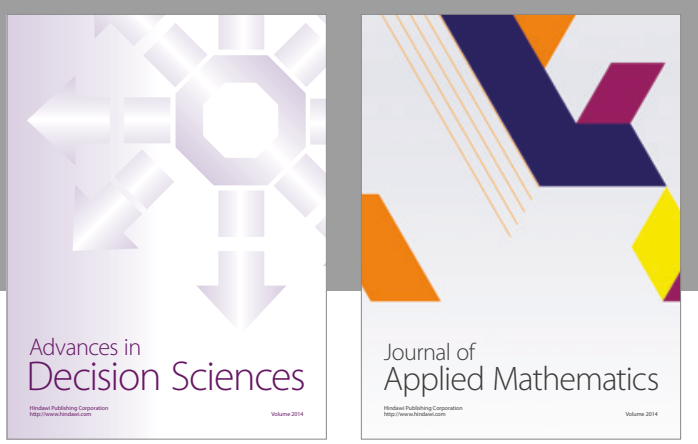

Algebra

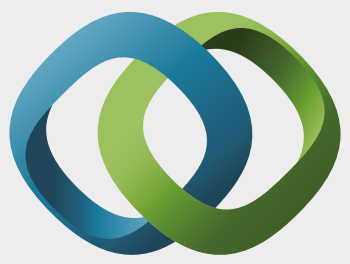

\section{Hindawi}

Submit your manuscripts at

https://www.hindawi.com
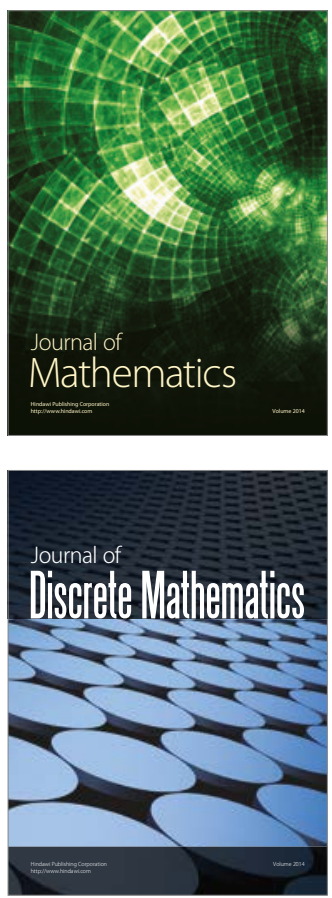

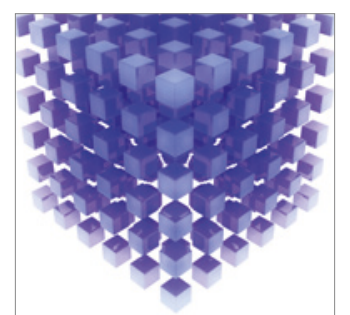

Mathematical Problems in Engineering
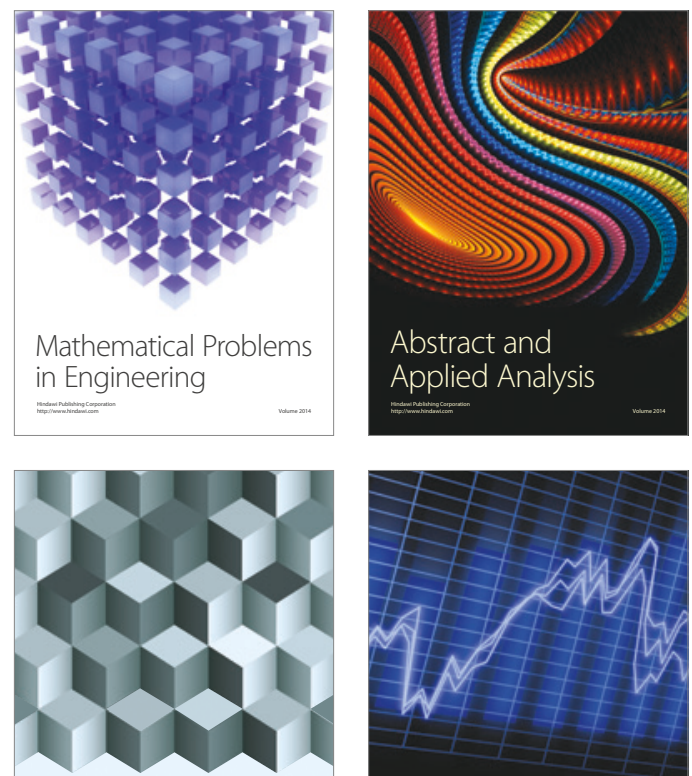

Journal of

Function Spaces

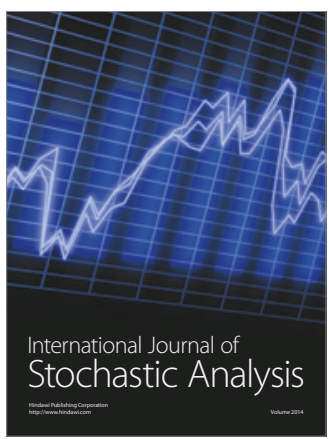

Probability and Statistics
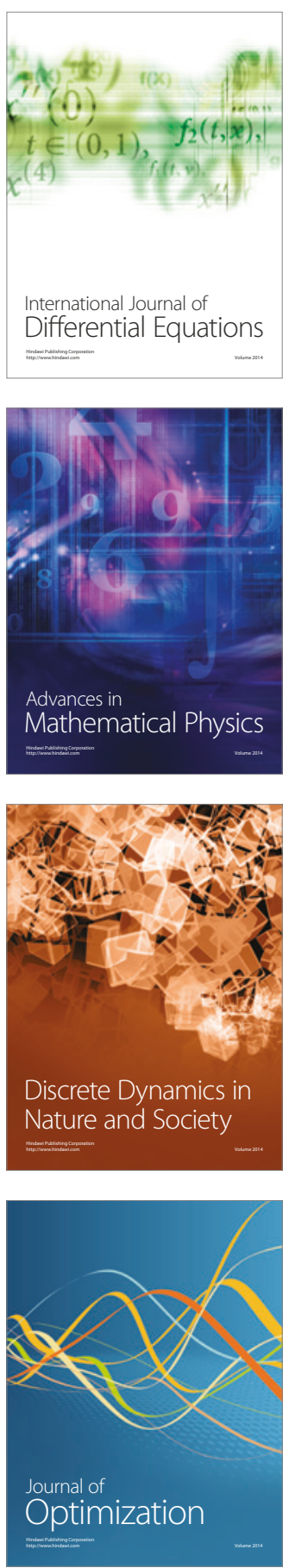